\title{
The Relation between Storm Risk and Wind and Wave Forecast Accuracy in the North Atlantic Ocean
}

\author{
D. Zastrau, M. Schlaak, T. Bruns, R. Elsner, and O. Herzog
}

\begin{abstract}
Oceanic storms are the main reason for shipping delays in the North Atlantic Ocean, due to the uncertainty in the forecast of tropical cyclones and extra tropical winter storms. This work investigates the relation between the statistical storm risk and the accuracy of the wind and wave forecast in the North Atlantic. The evaluation is based on historical wind and wave forecast data from the German Weather Service (DWD) between August, 2005 and November, 2010. First of all the regional storm risk in the North Atlantic is assessed. For this purpose 11 different storm clusters have been identified in the historical weather data with a non-parametric clustering algorithm. It shows that the storm risk varies between the storm clusters regionally as well as seasonally. Furthermore a correlation was found between the storm risk and the wind speed and wave height forecast root mean squared error (RMSE). The results allow for estimating future forecast accuracy based on the assessment of the regional and seasonal storm risk.
\end{abstract}

Index Terms-Wind and wave forecast accuracy, North Atlantic Ocean, storminess, risk management.

\section{INTRODUCTION}

The primary purpose of oceanicship weather routing is the avoidance of storms. The extreme weather conditions affect fuel consumption, safety and travel time.40\% of today's cargo ships arrive at their destinations with at least one day of delay [1]. This is primarily due to the uncertainty in the numerical weather forecasts (wind and waves). Whereas transatlantic routes typically take between 10 and 22 days, numerical weather forecasts are only available for a look-ahead time of 7-10 days. The mean track error for tropical storms (Fig. 1) is about 250 sea miles for a 120 hours forecast horizon. However this is just a mean value which varies seasonally and geographically. The propagation speed of depressions in winter is bigger than in other seasons over the central North Atlantic areas, with ca. $70 \%$ of cyclones moving at speeds of $12 \mathrm{~ms}^{-1}$ [2]. In late spring slowly moving cyclones often exist close to Newfoundland, corresponding to the time of the most frequent blocking action over the eastern North Atlantic. Also the storms themselves potentially impact the forecast accuracy due to increased

Manuscript received March 15, 2014; revised June 5, 2014. This work has been supported by the government of Lower Saxony (Niedersächsisches Vorab. F. A.), Germany.

D. Zastrau and R. Elsner are with ANWI Institute, HS Emden-Leer, Germany (e-mail: david.zastrau@wirtschaft.hs-emden-leer.de, reinhard.elsner@hs-emden-leer.de).

M. Schlaak is with EUTEC Institute, HS Emden-Leer, Germany (e-mail: michael.schlaak@hs-emden-leer.de).

O. Herzog is with TZI, University of Bremen, Germany and Jacobs University, Bremen (e-mail: herzog@tzi.de).

T. Bruns is with German Weather Service (DWD) (e-mail: thomas.bruns@dwd.de). atmospheric turbulences which are more difficult to predict by the forecast model. Studies indicate that storm frequencies and intensities are decadal shifting in the North Atlantic due to the long-term El Nino pattern or gradually displacement of the main North Atlantic Hurricane Track [2]. Also the weather forecast accuracy improved gradually during the last decades. Therefore this research investigates the link between storms and local forecast accuracy based on weather forecasts from the last decade.

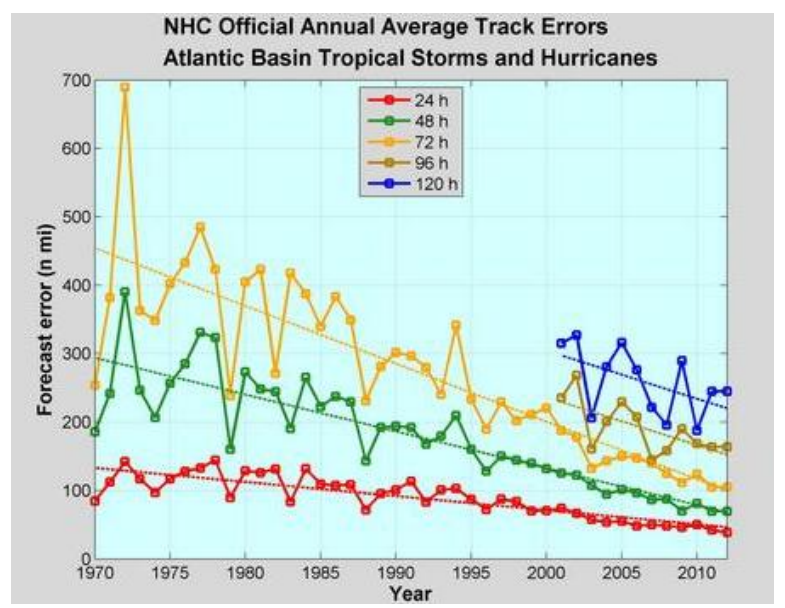

Fig. 1. Annual average official track errors for Atlantic basin tropical storms and hurricanes for the period 1970-2012, with least-squares trend lines superimposed (http://www.nhc.noaa.gov/verification/).

\section{WIND AND WAVE FORECASTS}

This work is based on wind and wave forecasts by the German Weather Service (DWD) from August, 2005 to November, 2010 [3]. The significant wave height (SWH) is defined as the mean wave height in meters (trough to crest) of the highest third of the waves. The wind speed $\left(\mathrm{ms}^{-1}\right)$ and direction $\left(^{\circ}\right)$ are 10 metre mean values. The forecasts were generated by the DWDs Global-European Model (GME). The "E" for European refers to the historic European forecasting model (EM). The GME is one out of 14 global weather forecasting models. It operates on triangular grid elements with a resolution of 346 square kilometres. Four times a day all meteorological reports available within a few hours of the datum time (known as $t+0$ ) are assimilated by the model's analysis scheme to define conditions at the datum time. This assimilation describes the current condition. The forecast is calculated based on this assimilation in 3-hourly intervals out to 174 hours, i.e., more than 7 days. The wind field forecasts in this work are given in terms of the forecasting look-ahead time $t_{i}: t+t_{1}$. It is noteworthy that the forecasts are mean values which describe whole regions and are fitted against each other to provide a coherent global representation. A recent study has shown that there is some 
seasonal but no significant geographical variability of the DWD wind forecast accuracy in the German North and Baltic Seas (for a detailed evaluation, see [4]). This work will validate those results on an oceanic scale. The $10-\mathrm{m}$ wind speed forecasts $(t=0)$ are used to detect storms in the historical data. Existing publicdatabases with North Atlantic storm information are either inhomogeneous and with a focus purely on tropical cyclones [5] or do not contain data from the recent years [6]. This is due to the main purpose of this data to serve meteorologists to investigate climate trends in storminess.

\section{STORM DETECTION AND CLUSTERING}

To keep things simple storms will be represented just by their central position, i.e. longitude and latitude. The term storm refers here to any episode of strong winds produced by intense pressure gradients associated with an approaching or developing cyclone [2]. First of all the data is segmented into regions of high wind speed (storms), low wind speed, and land as shown in Fig. 2. Subsequently, a two-pass algorithm for region extraction is used to identify connected storm areas in the gridded forecast data. Finally, based on their geographical centre, the storms are grouped into 11 different clusters by a mean shift clustering algorithm. The evaluation will later investigate variations in the forecast accuracy between the different clusters.

\section{A. Threshold-Based Segmentation of Wind Speed Data}

The weakest storms on the Saffir-Simpson hurricane wind scale are tropical depressions with sustained wind speeds (10-min) of $17 \mathrm{~ms}^{-1}$. Since the GME analysis data are 3-hourly mean values a smaller threshold of $15 \mathrm{~ms}^{-1}$ is used here. Thus the wind speed data is segmented into regions of high wind speed, low wind speed, and land. A two-pass algorithm is used to extract the connected regions of high wind speed from the gridded data.

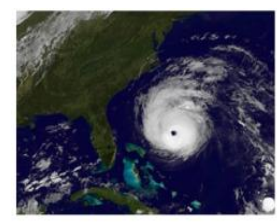

a)

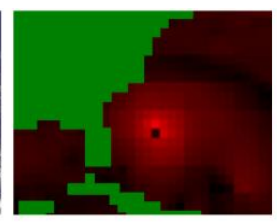

b)

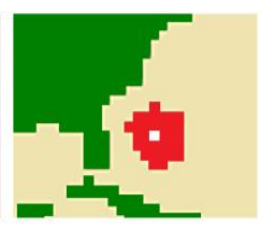

c)
Fig. 2. Threshold based segmentation of gridded wind speed data. A storm (a) is identified by the $10-\mathrm{m}$ offshore wind speed data (b). Wind speeds greater than $15 \mathrm{~ms}^{-1}$ (red) are separated from land (green) and other data (c). The example shows a NASA satellite image of Hurricane Earl (Sep 3, 2010).

\section{B. The Two-Pass Algorithm}

Two-pass algorithms [7] can be applied to extract regions with a specified value from an array of data. In this case the algorithm is used to extract the storm regions from the wind data. The algorithm's name originates from its basic concept to process the input data twice. The first pass assigns identical labels to adjacent storm coordinates, thus relating them to the same storm. The second phase resolves labels which are referring to the same storm and replaces them with a unique label. After processing the segmented wind speed data all storm regions have been uniquely labeled. The algorithm's computational complexity increases linearly with the number of data points. The processing of almost 4.000 weather observations ( 5 years in 12 hourly steps) takes approximately 4 hours on a standard PC.

\section{The Storm Properties}

After the storm regions have been extracted the DWD data is used to compute the maximum wind speed and wave height for each storm. The centre $(\bar{x}, \bar{y})$ of a storm is calculated by the second geometrical moment of its geographical coordinates in Eq. (1). The function $f(x, y)$ returns 1 if the coordinate $(x ; y)$ belongs to the storm, else it returns 0 .

$$
M_{i j}=\sum_{x=-180}^{180} \sum_{y=-90}^{90} x^{i} y^{j} f(x, y),(\bar{x}, \bar{y})=\left(\frac{M_{10}}{M_{00}}, \frac{M_{01}}{M_{00}}\right)
$$

Eq. 1 presentsgeometrical moments for a two-dimensional area. The mean of all longitudes $\left(M_{10}\right)$ and latitudes $\left(M_{01}\right)$ belonging to a storm divided by the area of the storm $\left(M_{00}\right)$ gives the centre of the storm $(\bar{x}, \bar{y})$.

\section{Clustering Storms with the Mean Shift Algorithm}

A clustering algorithm is used to identify dense regions of storms in the North Atlantic Ocean. The mean shift algorithm is a non-parametric algorithm, i.e., there are no embedded assumptions on the location of storm clusters or the number of clusters. The main idea of the algorithm is to treat the historical storms as an empirical density function (EDF) where dense storm regions correspond to the local maxima or modes of the underlying distribution (for further details, see [8]). The storms associated with the same mode are considered members of the same cluster. To estimate the EDF with Kernel Density Estimation a kernel bandwidth must be set. The bandwidth is estimated for a random sample $\mathrm{X}$ of storms using the average of the furthest distance between vectors in $\mathrm{X}$ to their $\mathrm{k}$ nearest neighbors (the bandwidth estimation technique is described in [9]). The algorithm has been successfully applied to similar tasks where no assumptions about the clusters were available. One downside of the algorithm is that the computation becomes unwieldy for high-dimensional data points because of the multidimensional range searching problem [10]. However in this case the data points are only 2-dimensional, since storms are just represented by their geographical centre $(\bar{x}, \bar{y})$, and the maximum wind speeds and wave heights are not considered as parameters for the geographical clustering. Thus the clustering of 1477 storm observations takes less than a minute on a standard PC and outputs 11 distinct geographical storm clusters as shown in Fig. 3.

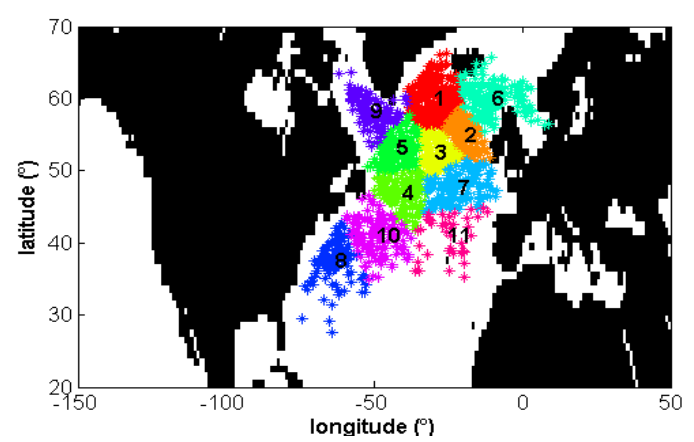

Fig. 3. Mean shift clustering of 1477 storm observations in the North Atlantic Ocean. Storms have been extracted from 10-m wind analysis data from the German Weather service in intervals of 12 hours between August 2005 and November 2010.The clusters have been identified based on density maxima of the storms central positions. 
It is noteworthy that not every point in Fig. 3 denotes a full storm track but just a single storm observation. From the perspective of risk management it is a more precise information how many storm observations have been made in a specific area over a given time period than how many distinct storms were present. The clusters 10,4,5,1 coincide with the typical North Atlantic Hurricane Tracks while the clusters 9,1,6 cover the extratropical cyclone track between Newfoundland and Northern Europe. The relatively small central clusters 2,3 indicate the potential of both tropical and extratropical cyclones leading to an increased storm observation probability.

\section{Evaluation: Assessment of Statistical StoRm RISK IN THE NORTH ATLANTIC OCEAN}

Apart from the storm frequencies the storm intensities are also of interest. From a shipping point of view the storm intensity can be defined by a storm's maximum wind speed and wave height. The evaluation has shown that the mean and maximum wind speeds were almost equal with $17 \mathrm{~ms}^{-1}$ and $26 \mathrm{~ms}^{-1}$ in the whole North Atlantic Ocean. The significant wave height on the other hand turned out to be approximately $1 \mathrm{~m}$ smaller in the North-West Atlantic Ocean(clusters $4,5,8,9,10$ in Fig. 4) than in the North-East Atlantic Ocean(clusters 2,7,11 in Fig. 4). The reason for this are most likely the long oceanic wave fetches (the distance over which the wind blows) which overlap with the coastal waves in the North-East Atlantic Ocean. Therefore distant oceanic winds are causing swell and thus are increasing the wave height in the North-East Atlantic Ocean.

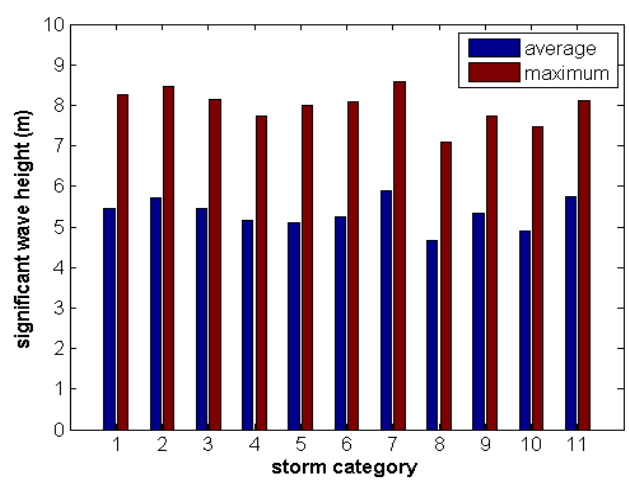

Fig. 4. Average and maximum significant wave height for storms in the North Atlantic Ocean between 2005 and 2010. The values are calculated for the centre of the storms where the mean wind speed is at least $15 \mathrm{~ms}^{-1}$.

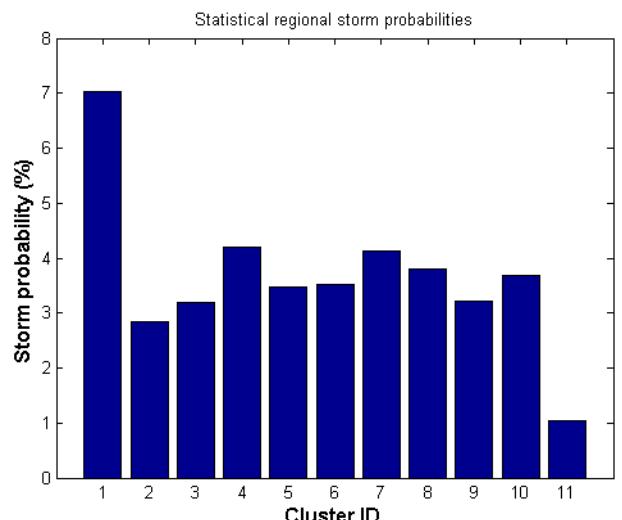

Fig. 5. Regional storm observation probabilities in North Atlantic Ocean between 2005 and 2010 . The probability was calculated by dividing the number of storm observations through the total number of observations.
Since there are only minor differences regarding the storm intensities, the next step is to investigate the regional probability to observe a storm as depicted in Fig. 5. The probability is empirically defined by the ratio between the number of historical storm observations and the total number of observations. Although most of the clusters are showing similar storm probabilities, it should be kept in mind that the cluster area sizes vary. Normalized to the area, the storm probability in clusters 2 and 3 is twice as high as in cluster 7 , because its area is approximately as big as the combined area of the clusters 2 and 3 .

The seasonal storm probability (Fig. 6) (i.e., the storm risk) increases during winter and decreases during summer. The seasonal storm risk varies by up to $18 \%$. Similarly as in Fig. 5 clusters 1 and 11 are showing above and below average storm probabilities whereas the other clusters do not show systematic differences. All clusters exhibit the same apparent wing towards a distinct two-season winter/summer pattern in storminess which has been associated with the seasonalclimatology of the jet stream and the midlatitude westerlies [11], [12]. In other words, during summer the atmospheric temperature gradient in the North Atlantic is not high enough to enable cyclonic turbulences.

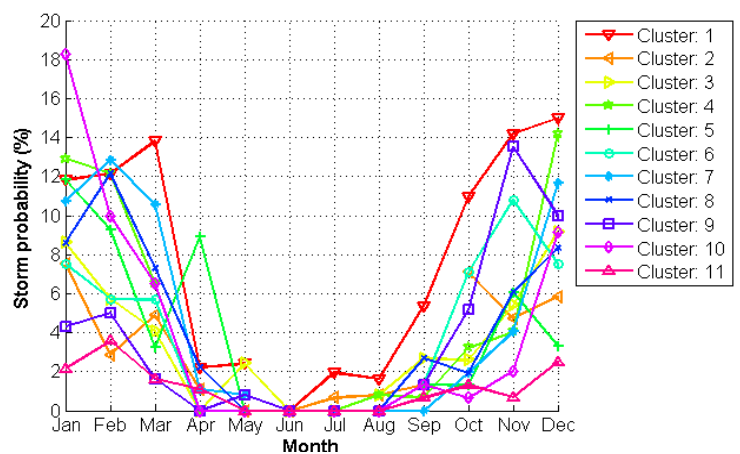

Fig. 6. Seasonal storm observation probabilities in North Atlantic Ocean between 2005 and 2010 . The probability was calculated by dividing the number of storm observations through the total number of observations.

These results complemented with the storm clusters in Fig. 3 are showing the regional and seasonal storm observation probabilities. Whereas the storm intensities do not vary in the mean aside from minor longitudinal differences with respect to the wave height, the storm frequencies are showing geographical and seasonal variability. The statistics can be applied to transatlantic shipping routes for which the travel time exceeds the weather forecast horizon. The remainder of the route can be planned based on the statistical information, since there is no other forecast information available. Also the results can be used to verify the statistical plausibility of a forecasted storm track.

\section{EVAlUATION: CORRELATION BETWEEN STATISTICAL STORM RISK AND FORECAST ACCURACY}

The second part of the evaluation investigates the relation between the weather forecast accuracy and the storm risk. To this end the forecast RMSE in Eq. 2 is correlated with monthly storm probabilities from Fig. 6.

$$
R M S E=\sqrt{\frac{\sum_{t=1}^{n}\left(y_{t}-\hat{y}_{t}\right)^{2}}{n}}
$$


Eq. 2 given a time series with $n$ predictions $\hat{y}_{t}$ and observations $y_{t}$ at point $t$ in time the root mean squared error (RMSE) is a robust estimator of the errors standard deviation.

A cubic polynomial fit (blue line) shows the forecast error incline with increasing storm risk in Fig. 7.

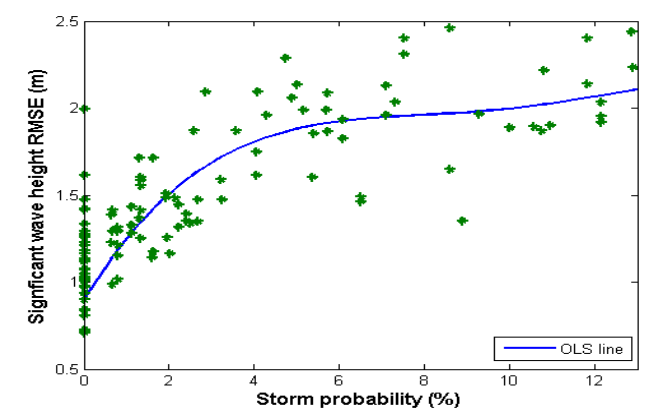

Fig. 7. Monthly storm probabilities in different clusters and the corresponding monthly wave forecast RMSE. The trend line shows a positive

correlation between storm probability and the $120 \mathrm{hrs}$ forecast error.

During months with $0 \%$ storm probability the mean forecast RMSE $\left(t_{i}=120\right)$ is roughly about $1 \mathrm{~m}$. The error increases by approximately $100 \%$ to more than $2 \mathrm{~m}$ for monthly storm probabilities of more than $6 \%$. Obviously since the storm frequency is correlated with the time of the year (see Fig. 6) the correlation also reflects the seasonal variation of the forecast error. However the storms directly show atmospheric dynamics which may cause forecast uncertainty whereas the time of the year is only an indicator for the true weather dynamics which varies annually. Since the wind speed and the wave height forecasts are correlated with each other (the wind speed is input to the wave model) the wind speed RMSE correlates similarly with the storm probability. The wind direction forecast accuracy on the other hand did not relate to the storm risk. Fig. 8 shows again the seasonal and geographical wave height forecast error.

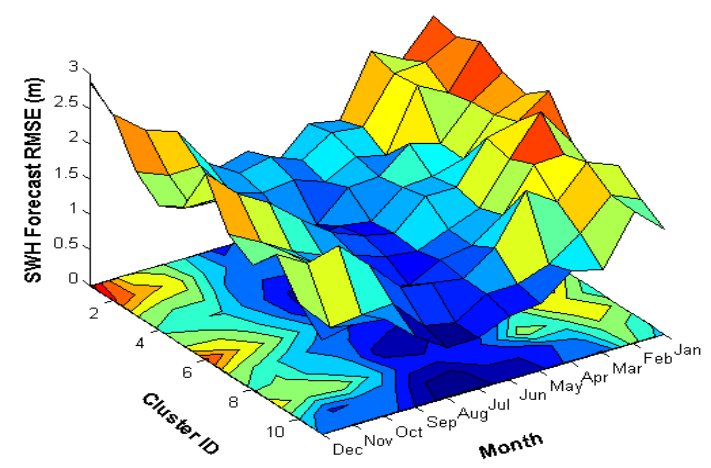

Fig. 8. Monthly significant wave height (SWH) 120 hrs forecast root mean squared error (RMSE) for 11different clusters in the North Atlantic Ocean.

Apparently the clusters 1,2,6 in the vicinity of the trough of Icelandic low pressure are showing the highest forecast error during winter.Especially cluster 1 and 11 are showing the correlation between storminess (Fig. 5) and forecast RMSE in Fig. 8. Since the previous results in this section referred to forecasts with a look-ahead time of $120 \mathrm{hrs}\left(t_{i}=120\right)$ it is now time to investigate the forecast accuracy over $t_{i}$ in the different clusters. Fig. 9 shows that the forecast accuracy in parts of the North East Atlantic (cluster 4,5,10) does almost not decrease whereas the accuracy for the clusters near to the trough of Icelandic low pressure decreases. Considering that the $t_{i}=24$ forecast accuracy is equal for most of the clusters it becomes evident that Fig. 8 would have shown little regional differences if the $t_{i}=24$ RMSE would have been used instead of the $t_{i}=120$ RMSE. This implies that the storms primarily impact the forecast accuracy of the medium-range forecasts of at least $48 \mathrm{hrs}$. Provided that the absolute wave heights in the southerly clusters $(10,11)$ are smaller than in the Northern clusters the relative forecast errors are not showing significant differences.

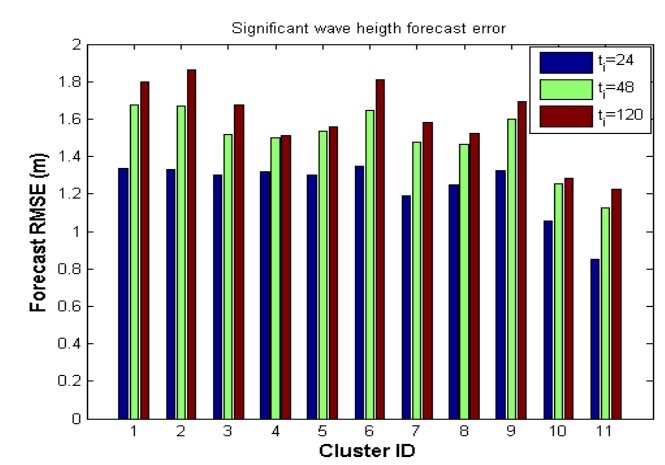

Fig. 9. Significant wave height forecast RMSE for different clusters with different forecast horizons between 1 and five days.

The wind speed forecast RMSE (Fig. 10) seems to be less predictable than the significant wave height even though both are related because of the wind waves which are generated by the current wind.

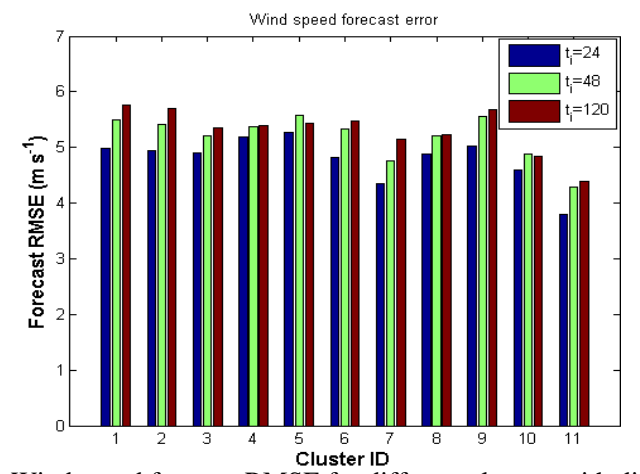

Fig. 10. Wind speed forecast RMSE for different clusters with different forecast horizons between 1 and five days

Finally the wind direction forecast accuracy is also of interest for weather ship routing even though the results showed that it does not correlate with the storm risk. Fig. 11 shows only minor differences between the clusters.

Apparantly the forecast RMSE in cluster 10 does not significantly change between a forecast horizon of $48 \mathrm{hrs}$ and $120 \mathrm{hrs}$. This was also observed for the wave height and the wind speed forecasts.

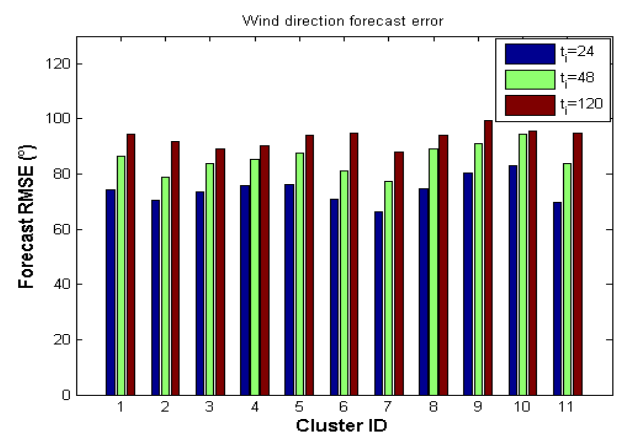

Fig. 11. Wind direction forecast RMSE for different clusters with different forecast horizons between 1 and five days. 


\section{CONCLUSION}

This work investigated the storm risk variability in the North Atlantic Ocean and its correlation with numerical weather forecast accuracy.

\section{A. Geographical and Seasonal Storm Risk}

The storm risk varies geographically and seasonally. High storm risk in the North-West Atlantic is contrasted with low storm risk in the South-East Atlantic. A distinct two-seasonal pattern with most storms occurring during the winter period between September and March has been observed. The mean storm intensities were homogeneous apart from approximately $1 \mathrm{~m}$ higher wave heights in the eastern North Atlantic. The statistical storm risk can be applied to weather ship routing for routes for which the travel time exceeds the weather forecast horizon of 7-10 days.

\section{B. Correlation between Storm Risk and Forecast Accuracy}

Those months with higher storm risk showed an increased wind speed and wave height forecast RMSE. Also the wind speed and wave height forecast RMSE showed the same apparent swing towards a distinct two-season winter/summer pattern in storminess as the storm risk with high forecast RMSE during winter. In contrast, the wind direction forecast accuracy did not visibly correlate with the storm risk and showed neither seasonal nor geographical variability. The correlation between the storm risk and the wind speed and wave height forecast RMSE can be applied to estimate future forecast confidence intervals in weather ship routing.

\section{REFERENCES}

[1] Vernimmen, W. Dullaert, and S. Engelen, "Schedule unreliability in liner shipping: origins and consequences for the hinterland supply chain," Marit Econ Logist (Maritime Economics \&\#38; Logistics), p. $1,2007$.

[2] I. Lozano, R. J. N. Devoy, W. May, and U. Andersen, "Storminess nd vulnerability along the Atlantic coastlines of Europe - analysis of storm records and of a greenhouse gases induced climate scenario," Marine Geology, pp. 2796-2801, 2004.

[3] D. B. D. Wetterdienst. German Weather Service. [Online]. Available: http://www.dwd.de

[4] D. Zastrau, M. Schlaak, T. Bruns, R. Elsner, and O. Herzog, "Differences in wind forecast accuracy in the German North and Baltic Seas," International Journal of Environmental Science and Development, April 2014.

[5] S. Carl \& National Center for Atmospheric Research Staff. The Climate Data Guide: IBTrACS: Tropical cyclone best track data. [Online].

Available: https://climatedataguide.ucar.edu/climate-data/ibtracs-tropical-cyclon e-best-track-data

[6] National Climatic Data Center, NOAA, "GTECCA (Global Topical and Extratropical Cyclone Climatic Atlas)," U.S. Department of Commerce, 1996.

[7] K. Wu, E. Otoo, and K. Suzuki, "Optimizing two-pass connected-component labeling algorithms," Pattern Analysis and Applications, pp. 117-135, 2009.

[8] Y. Cheng, "Mean shift, mode seeking, and clustering," IEEE Transactions on Pattern Analysis and Machine Intelligence, pp. 790-799, 1995

[9] D. Comaniciu and P. Meer, "Mean shift: A robust approach toward feature space analysis," IEEE Transactions on Pattern Analysis and Machine Intelligence, pp. 603-619, 2002.

[10] P. K. Agarwal, Handbook of Discrete and Computational Geometry: Range Searching, CRC Press, Inc., 1997, pp. 575-598.
[11] R. Dolan, H. Lins, and B. Hayden, "Mid-Atlantic coastal storms," Journal of Coastal Research, pp. 417-433, 1989.

[12] J. Sweeney, "A three-century storm climatology for Dublin 1715-2000," Irish Geography, vol. 33, pp. 1-14, 2000.

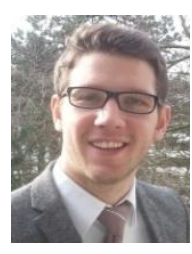

David Zastrau received the diploma degree in computer science from the University of Bremen, Germany, in 2011. He is a doctoral candidate at the International Graduate School for Dynamics in Logistics in Bremen. His research interests include machine learning, support vector machines, maritime logistics, and uncertainty in numerical meteorological weather forecasting for weather ship routing.

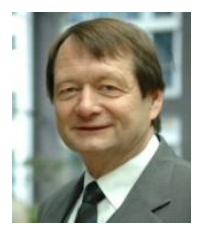

Otthein Herzog received his MSc degree in mathematicsfrom the University of Bonn, Germany in 1972, and got his PhD degree in computer science from the University of Dortmund, Germany, in 1976.

He worked for IBM Germany in various technical and managerial positions in software-related R\&D from 1977 to 1993 . From 1993-2009, he held the position of the chaired professor of artificial intelligence at University of Bremen, Germany. Since 2010 he holds the wisdom professorship of visual information technologies at Jacobs University Bremen. Since 1998 he also holds an affiliate professorship at the Machine Learning and Inference Laboratory of the George Mason University, Fairfax, VA, USA. His research interests include wearable computing, knowledge management of multi-agent systems, and the semantic analysis of images and videos in which fields he has (co-) authored more than 260 scientific publications.

Dr. Herzog is a fellow of GI, the German National Computer Society, member of the ACM, and an elected fellow of ACATECH - German National Academy of Science and Engineering. He also serves on various boards of German research institutions and enterprises as well as the CEO of a technology transfer company.

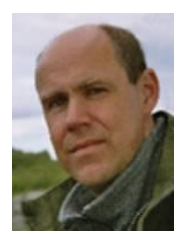

Thomas Bruns received the diploma degree in meteorology from University of Hamburg, Hamburg, Germany, in 1981, and the PhD degree from Max-Planck-Institute for Meteorology, Hamburg, Germany, in 1985.

In 1987, he joined the Deutscher Wetterdienst (DWD, German Weather Service) in Hamburg, specializing in marine and arctic meteorology, ocean wave modeling, ship routing, marine weather forecast, aviation weather forecast. Currently, he is the head of the Marine-Meteorological Consulting Office and member of the JCOMM- Expert Team on Waves and Coastal Hazards Forecasting Systems.

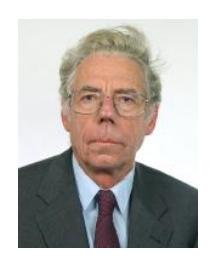

Michael Schlaak studied physics and physical chemistry at the Technical University of Darmstadt, Germany. He received his $\mathrm{PhD}$ degree in 1971 and the habilitation in physical chemistry in 1976; After 10 years in chemical industry he became a professor at the University of Applied Sciences (Hochschule Emden-Leer), Emden, Germany, in 1986, teaching physical chemistry, environmental technologies and process control; in 1996, he established the research institute EUTEC (Environmental Technologies, Emden) and was its director until 2008; Co-operations with several universities in different countries. His research fields include environmental technologies and process control.

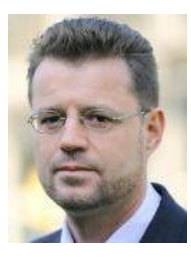

Reinhard Elsner studied mathematics and received his $\mathrm{PhD}$ degree at the University of Göttingen in 1992 on strategic route planning. After 5 years in industry he became a professor at the University of Applied Sciences (Hochschule Emden-Leer) in Emden, Germany, teaching economy informatics, statistics, logistics and project oriented learning. He established the institutes ANWI (Applied economy research and regional analysis) and HILOG (Institute of Logistics) and is the director of both institutions. He is a member of the German Traffic Association. 



\section{Environmental Quality Monitoring}


